\title{
An intelligent order allocation system for effective order fulfilment under changing customer demand
}

\author{
K.H. Leung ${ }^{1, *}$, K.L. Choy ${ }^{1}$, and H.Y. Lam ${ }^{1}$ \\ ${ }^{1}$ Department of Industrial and Systems Engineering, The Hong Kong Polytechnic University, Hung Hom, Kowloon, Hong Kong
}

\begin{abstract}
In today's intense global competition, problems still exist under the umbrella of Just-in-Time application in the field of order management. The management of a firm usually faces difficulty in allocating stock to fulfil customer order, especially in the case of receiving a sudden change request from customers. In order to ease order allocation issues aroused by JIT, an intelligent system, namely, Intelligent Sales Order Handling System (ISOAS), is developed through the integration of fuzzy-AHP approach for decision making process in order allocation. This approach enables the selection of desired sales orders based on multiple criteria which may be quantitative or qualitative in nature, according to the judgment of scholars and domain experts. With ISOAS, customer orders are prioritized with respect to the values according to their performance under each decision making attributes. The degree of confidence of the decision judgements are quantified through the spread of fuzzy numbers with fuzzy pairwise comparison calculations. The approach can transform the fuzziness of human preference into the measurable number, enabling the operation of the AI-based system to assist humans in decision-making. An order allocation case study in a logistics department is demonstrated in this study. Results indicate an improved efficiency during the decision making process.
\end{abstract}

\section{Introduction}

Just-in-time (JIT) is one of the popular production methodologies in supply chain management system. It aims to regulate customer orders with the right amount just in the right time. The main goal of this phenomenon is to significantly decrease inventories, and to effectively control the customer demand with the production line or the delivery system [1].

JIT operations can be involved in many functional areas of a company, such as procurement, manufacturing and delivery. For manufacturing operations, make-tostock (MTS) and make-to-order (MTO) are one of the examples in lean manufacturing system. MTS matches production and inventory with consumer demand forecasts, determining the amount of stock to be produced before actual order requirements are made. Customer needs are fulfilled by sending out the finished product from the stocks, such as the household appliances, standard parts, cars and other production parts; In MTO environment, prompt actions are made only after the receipt of a customer order, indicating stockless production. According to the study given by Olhager and Prajogo [2], companies would decide to choose which lean strategy based on different criteria driven by market structures, process type, supplier's behaviour [3].

In regard to the advantages brought by JIT, such as lower inventory holding cost, however, a company may not be able to instantaneously meet the requirements of an unexpected order, since it has few or even no stocks of finished goods. Under the JIT approach, the whole planning can be disrupted by a small change in customer request. However, uncertainties frequently exist in the customer side, such as any change in customer requested arrival date for goods delivery, or an unpredictable sales order is being placed. These uncertainties may lead to an increase in the inventory or stock shortage in the supply chain, which would totally violate the intention of JIT operations. The change in the number of resources to be delivered and schedule requires prompt actions to rearrange the procurement details, manufacturing progress, logistics planning, and even for the product installation in site for some special products like laboratory equipment. Sharma [4] agreed that storage can provide a buffer for discontinuous demand to a certain degree. Since the discontinuous demand does not have repetitive demand pattern, it is difficult to forecast when and how many stock is needed to be ready, a precise amount of stock can settle the sudden upraise or changes of customer requests. Nonetheless, storage is a type of waste in the business process. It occupies the space and increase the costs of warehouse management, and hence the company may get the capital loss and violates the original concept of JIT.

In an effort to rectify the obstacles found in MTO supply chain, in which order reallocation may be needed in case of any unexpected change in sales order

\footnotetext{
* Corresponding author: eric.kh.leung@,connect.polyu.hk
} 
requested by a customer, this study proposes an intelligent decision support system, integrating fuzzyAHP approach and rule-based system, for customer prioritization and order allocation in case of having insufficient stock to handle all the customer orders. Through the decision support generated by the proposed approach, a company is able to properly allocate the limited stock to the most appropriate customer while minimizing the undesired effect due to the issue of the shortage of stock.

\section{Literature review}

Customer selection process is an essential operating procedure in a company. Improper selection of customer could lead to the loss of sales and reputation. Conventionally, decision makers generate customer selection decisions based on their own experiences and simple techniques to choose for the best customer. Yet, it requires a lot of time for drawing a conclusion through data collection and irregular meetings. In the mainstream literature, studies that aim to deal with the inadequate resources problem by selecting most suitable customers for allocating the scarce amount of inventories in supply chain management is inadequate. This is understandable given that the importance of allocating limited resources for the right customer within the specific time in related to the firm's profitability in long term was not fully recognized by many academicians and specialists. The development of the analytical approach for standardizing the decision making process in solving this kind of supply chain management problem has been limited, although there are some customer selection approaches suggested in the aim of maximizing the company's profit.

In the previous literature, the only available technique in customer selection process is the customer lifetime value (CLV) analysis. The earliest scholars [5] proposed a mathematical model for determining customer lifetime value, so as to enhance the customer acquisition decision-making process or making customer retention trade-offs scientifically. The CLV calculates the present value of the aggregate expected marginal profits over time minus the cost of serving the customer [5,6]. In CLV analysis, firms can measure customer profitability and determine the profitability distribution within the customer based by using the past sales and service data. Based on customer profitability analysis, the company can assign the right amount of resources by selecting profitable customers and sustain long-term profitable relationships. Yet, there are some noticeable concerns for CLV analysis being inapplicable to the decision making process in customer selection when dealing with resource allocation problem. Since the CLV mathematical approach is mostly a cost-benefit analysis technique, only some quantitative parameters are taken into account, such as the predicted purchase quantity, the contribution margin for a single item, the number of contacts to customer, and the unit marketing cost [7]. Other important qualitative factors may not be considered comprehensively in the decision making process, which in turn reduce the preciseness of the judgment in customer selection. Furthermore, when there is not enough stock provided to all customers, the customer selection and order allocation decision making process should not only consider the customer value in the basis of cost-benefit analysis, but also seeing the surrounding environmental factors as a whole. Concerning the complexity in the supply chain system, every single parameter in each stage can be significant for striving the optimal solution in customer selection and order allocation. Without considering some other qualitative and quantitative factors, CLV analysis cannot completely support the decision making process for the stated problem.

In the selection process, Multiple Criteria DecisionMaking (MCDM) methods are frequently applied to solve complex real world problems that explicitly evaluate multiple, conflicting, and disproportionate criteria and/or objectives for possible selection of the suitable alternative [8]. These criteria have their uniqueness and different degree of importance in the measurement. In the later development, the Analytic Hierarchy Process (AHP), a systematic decision-making tool to solve multi-criteria decision making problems as initially proposed by Saaty [9], has recently become popular and considered to be more consistent than the original approach. It decomposes a complex MCDM problem into a system of hierarchies by standardizing the numeric scale for the measurement of quantitative as well as qualitative performances. The objective, criteria, sub-criteria and the decision alternatives are constructed at the first level, second level, third level and fourth level respectively. The measurement of the attributes in the same level involves pair-wise comparisons using Eigenvalue approach. The hierarchy approach used in AHP delivers various advantages. AHP helps to integrate a group of different criteria with consensus [10]. It solves complicated problems which involve the consideration of multiple criteria and alternatives concurrently. It has the ability to integrate data and human judgement into the model in a logical way. The ease of usage and the conversion of subjective feelings in prioritizing alternatives makes AHP an important contribution in the MCDM process. Although AHP has been widely adopted to solve the multi-criterion decision making problems, its most important drawback is that the use a scale of 1 to 9 cannot be handled the uncertainty decisions when making comparison of the attributes. It may not be certain for the decision makers to assign a discrete value of the pairwise judgement. Therefore, the decision maker needs more than the distinct nine-point scale to describe the vagueness. Regarding this, triangular fuzzy numbers (TFNs) can be used to decide the priority of one decision variable over another. Synthetic extent analysis method for formulating the final priority weights based on TFNs is called fuzzy-AHP [11]. In the past decade, fuzzy-AHP approach has been widely applied across various field for tackling multiple-criteria decision-making problems. Shaw et al. [12] proposed the use of fuzzy-AHP and fuzzy multi-objective linear programming for developing supplier selection for low carbon supply chain. 
Büyüközkan et al. [13] introduced a strategic analysis of healthcare service quality using fuzzy-AHP methodology. Wang et al. [14] developed a two-stage fuzzy-AHP model for risk assessment of implementing green initiatives in the fashion supply chain. Therefore, this study proposes the use of fuzzy-AHP approach for the customer selection and order allocation in case of having insufficient stock to fulfil all customer orders.

\section{Architecture of the proposed solution}

In order to manage the customer interruption in the supply chain, the human judgement for the re-planning decision should be transformed into a standardised model with mathematical support. Therefore, an Intelligent Sales Order Allocation System (ISOAS) is proposed for reengineering the conventional decision making process. With the use of ISOAS, the decision support provided by the suggested approach systematically enables the decision maker to organise all the attributes involved in the decision making judgement and identify the most desirable customer order for distributing the limited amount of product, instead of drawing conclusion after long discussion process each time. ISOAS is a business intelligent application which comprises two modules, they are (i) order collection and processing module, and (ii) customer selection and resource allocation module.

\subsection{Order collection and processing module}

The database of ISOAS is the information storehouse for collecting, storing and sorting four main types of data: (i) sales order details, which are entered into the system according to the information stated in the contract signed by the customer and the firm, and (ii) the purchase order information which is retrieved from the supplier side, and (iii) the inventory records of the company warehouse, which are changeable information and varies with the inflow and outflow of sale order and purchase order, and (iv) the customer records.

Sales orders are generated after the company successfully signed the product delivery agreement with the customer. The detail information of one sales order including customer name, consignee's address, order item information, order quantity, request delivery date, etc. will be initially input into the company's database or the current ERP system. Then the information will be matched with the inventory data to proceed for delivery scheduling or issuing purchase order. The purchase order and inventory record will then be entered into the database. When the company face the problems of having inadequate amount of products to fulfil all the customer's order because of disruption of customer request or the delay in the supplier's goods arrival, rescheduling is the indispensable action. After all the related information is collected, the ISOAS will be activated to generate decision support for allocating the limited resources to the right customer at the right time.

\subsection{Resource allocation module}

This module provides decision support for the decision makers to decision the exact amount of stock to allocate to the specific customer. A fuzzy-AHP approach is introduced to generate the decision support. Several procedures are required to follow in a progressive way, as depicted in Table 1.

Table 1. Fuzzy AHP sequence for customer prioritization.

\begin{tabular}{|c|c|}
\hline Sequence & Description \\
\hline 1 & Criteria Identification \\
\hline 2 & $\begin{array}{c}\text { Fuzzy pairwise comparison for evaluating } \\
\text { the weightings between criteria }\end{array}$ \\
\hline 3 & $\begin{array}{c}\text { Fuzzy pairwise comparison for evaluating } \\
\text { the performance of the alternatives under } \\
\text { each criterion/sub-criterion }\end{array}$ \\
\hline 4 & $\begin{array}{c}\text { Score calculation for each customer order } \\
\text { Customer order selection }\end{array}$ \\
\hline 5 & \\
\hline
\end{tabular}

\section{Step 1. Criteria Identification}

The AHP hierarchy structure is broken down from the overall goal, into second level of evaluation criteria and the third level of sub-criteria. The consideration of choosing the criteria is based on the expertise of the decision maker and domain professionals from real life experience in the logistics industry. The formulation of those criteria is established according to the general situation for firms that are facing the similar problem. In this study, three criteria and eight sub-criteria are identified for the selection of customer orders, as shown in Table 2.

Table 2. Evaluation criteria for customer prioritization.

\begin{tabular}{|c|c|}
\hline Criteria (Level 2) & Sub-criteria (Level 3) \\
\hline \multirow{3}{*}{$\begin{array}{l}\text { Customer relations } \\
\text { (C1) }\end{array}$} & $\begin{array}{l}\text { Customer relationship rating } \\
\text { (S1) }\end{array}$ \\
\hline & $\begin{array}{l}\text { Switching cost } \\
\text { (S2) }\end{array}$ \\
\hline & $\begin{array}{l}\text { Order regularity } \\
\text { (S3) }\end{array}$ \\
\hline \multirow{2}{*}{$\begin{array}{l}\text { Cost for delayed } \\
\text { shipment } \\
\text { (C2) }\end{array}$} & $\begin{array}{l}\text { Penalty cost of delayed shipment } \\
\text { (S4) }\end{array}$ \\
\hline & $\begin{array}{c}\text { Shipment cost increment for } \\
\text { delayed shipment } \\
(S 5)\end{array}$ \\
\hline \multirow{3}{*}{$\begin{array}{l}\text { Profitability } \\
\text { (C3) }\end{array}$} & $\begin{array}{l}\text { Net profit } \\
\text { (S6) }\end{array}$ \\
\hline & $\begin{array}{c}\text { Average profit per order } \\
(S 7)\end{array}$ \\
\hline & $\begin{array}{l}\text { Total profit contribution } \\
\text { (S8) }\end{array}$ \\
\hline
\end{tabular}


Step 2. Fuzzy pairwise comparison for evaluating the weightings between criteria

After constructing the AHP hierarchy structure with criteria and sub-criteria level, pairwise comparison of each decision making components in the particular level should be made. Since it is difficult to translate the human subjective judgement into some discrete values, the fuzzy logic is introduced to represent the fuzziness of subjective values. With the use of the Fuzzy Triangular Scale modified from the AHP's fundamental 9-point scale (see Table 3), consequently, the upper triangular pairwise comparison matrix will be formed by the decision maker for calculating the corresponding weightings for each criteria/ sub-criteria.

Table 3. Fuzzy scale of the intensity of dominance of element $i$ over element $\mathrm{j}$ and its corresponding linguistic definition.

\begin{tabular}{|c|c|c|}
\hline $\begin{array}{c}\text { Saaty Scale } \\
\text { (Saaty, 1980) }\end{array}$ & $\begin{array}{c}\text { Fuzzy Triangular } \\
\text { Scale }\end{array}$ & $\begin{array}{c}\text { Importance of } \\
\text { one criteria/ } \\
\text { alternative over } \\
\text { another }\end{array}$ \\
\hline 1 & $\left(1_{x} 1_{x} 1\right)$ & Equal \\
\hline 2 & $(3-\delta, 3,3+\delta)$ & Weak \\
\hline 3 & $\left(5-\delta \delta_{x} 5+\delta\right)$ & Fairly Strong \\
\hline 4 & $\left(7-\delta_{v} 7,7+\delta\right)$ & Very Strong \\
\hline 5 & $(9,9,9)$ & Absolute \\
\hline 2 & $\left(2-\delta_{v} 2,2+\delta\right)$ & \multirow{4}{*}{$\begin{array}{l}\text { The discontinuous } \\
\text { values between } \\
\text { two adjacent scales }\end{array}$} \\
\hline 4 & $(4-\delta, 4,4+\delta)$ & \\
\hline 6 & $(6-\delta, 6,6+\delta)$ & \\
\hline 8 & $\left(8-\delta \delta_{v} 8+\delta\right)$ & \\
\hline
\end{tabular}

$\delta$ is representing the degree of confidence in judgement by the stakeholder or the domain expert. Lower the value of $\delta$ means the judgement has higher degree of confidence. Table 4 gives an idea on the inversely relationship of $\delta$ to the degree of confidence.

Table 4. Degree of confidence linguistic scale.

\begin{tabular}{|c|c|}
\hline$\delta$ & $\begin{array}{c}\text { Degree of } \\
\text { confidence }\end{array}$ \\
\hline 0.5 & High \\
\hline 1 & Moderate \\
\hline 2 & Low \\
\hline
\end{tabular}

Step 3. Fuzzy pairwise comparison for evaluating the performance of the alternatives under each criterion/sub-criterion

Similar procedures are performed for evaluating the performance of the alternatives under each criterion and sub-criterion. The performance of the sales orders under each sub-criterion can be measured by both quantitative data and qualitative preference. For the comparison between alternatives under those quantifiable sub-criteria, it will not undergo the Fuzzy-AHP procedures. Rather, the measurement is by simple calculation for computing the corresponding values with the quantitative data driven from the company's database or by data input. For those sub-criteria which are difficult to measure, the extent analysis of Fuzzy-AHP procedures will be executed again. Table 5 shows the overall source of measurement of the alternatives' performance under each sub-criteria.

Table 5. Fuzzy scale of the intensity of dominance of element $i$ over element $j$ and its corresponding linguistic definition.

\begin{tabular}{|c|c|c|c|}
\hline Sub-criteria (Level 3) & Database & $\begin{array}{l}\text { Data } \\
\text { input }\end{array}$ & $\begin{array}{c}\text { Pairwise } \\
\text { comparis } \\
\text { on }\end{array}$ \\
\hline Net profit & $\checkmark$ & & \\
\hline Average profit per order & $\checkmark$ & & \\
\hline Total profit contribution & $\checkmark$ & & \\
\hline $\begin{array}{l}\text { Penalty cost of delayed } \\
\text { shipment }\end{array}$ & & $\checkmark$ & \\
\hline $\begin{array}{c}\text { Shipment cost } \\
\text { increment for delayed } \\
\text { shipment }\end{array}$ & & & $\checkmark$ \\
\hline $\begin{array}{l}\text { Customer relationship } \\
\text { rating }\end{array}$ & & & $\checkmark$ \\
\hline Switching cost & & & $\checkmark$ \\
\hline Order regularity & $\checkmark$ & & \\
\hline
\end{tabular}

Step 4. Score calculation for each customer order Through the standard computation procedures of FuzzyAHP, the performance for each customer order under each criterion and sub-criterion can be obtained. Then, the overall score for each customer order can be obtained.

\section{Step 5. Customer order selection}

The customer prioritization procedure of ISOAS is completed by selecting the candidate (i.e. a customer order) that gives the highest score calculated in Step 4 using Fuzzy-AHP computational procedures. The firm can then refer to the generated decision support of ISOAS to allocate a right amount of stock to the designated customers accordingly.

\section{A numerical example}

A numerical example using real data from a case company is given in this paper for better illustration of the proposed approach for customer order selection. 


\subsection{Implementation overview}

The case company is Hong Kong-based company actively involved in the health care industry. It primarily engages in the design, development, manufacture and distribution of analytical appliances, laboratory instruments and life science equipment. The company runs with two business segments, the manufacturing segment and the distribution segment. The manufacturing segment includes the design, production and sales of laboratory and analytical instruments and life science equipment; whereas the distribution segment is engaged in the distribution of those equipment to the end users, like for the hospitals, R\&D Centers, laboratories and tertiary institutions. Products are distributed via the company's distribution network to all customers around the globe.

Since the company executes the make-to-order business strategy, the manufacturing process or the procurement procedure starts after a customer order is received. Most of the product lead time is quite long, usually about 2 to 3 month to get the equipment from its own factory or the suppliers. Because of the time limitation, the supply chain planning in the company is tight and barely allowing for any schedule delay. In addition, there are usually interruptions caused by the customer to request for early delivery or delayed delivery. Also, some of the newly signed contracts by the company are very urgent order, with those customer requesting speedy delivery. With the sudden requests, and yet the company does not have enough stocks to fulfil all the customers' requirements, the company is required to re-plan the customer order sequence and procurement order for maximising the company's interest. One or more decision makers will be responsible for the new arrangement. The decision makers will have to consider which customer's order should be processed first for sending out the product with the limited capacity, and how many of them to be distributed to the selected customer. The decision making process only relies on their own personal judgement and experience and lack of systematic supporting evidence. In view of the current bottleneck, the prototype of ISOAS is implemented in an attempt to alleviate the problem.

The implementation of ISOAS in the case company starts with the development of a cloud database for data storage and retrieval, and the identification of criteria for the decision-making of customer order selection. With the criterion and the corresponding sub-criterion identified through experts' interviews and discussions, the weighting of each criteria and sub-criteria is calculated using fuzzy pairwise comparison. Three decision makers are required to indicate their preference of the importance for different criteria. An example of pairwise comparison matrix for identifying the weighting among criteria by one decision-maker is shown in Table 6.
Table 6. Pairwise comparison matrix of customer/sales order selection criteria prepared by one decision maker.

\begin{tabular}{c|ccc}
\hline Criteria & $\mathrm{C} 1$ & $\mathrm{C} 2$ & $\mathrm{C} 3$ \\
\hline $\mathrm{C} 1$ & $(1,1,1)$ & $\left.\frac{1}{4} \frac{1}{3} \frac{1}{2}\right)$ & $\left.\frac{1}{(6} \frac{1}{5} \frac{1}{4}\right)$ \\
$\mathrm{C} 2$ & $(2,3,4)$ & $(1,1,1)$ & $(4,5,6)$ \\
$\mathrm{C} 3$ & $(4,5,6)$ & $\left.\frac{1}{6} \frac{1}{5} \frac{1}{4}\right)$ & $(1,1,1)$
\end{tabular}

With all three pairwise comparison matrix developed by three decision makers, overall fuzzy comparison matrix of criteria, as shown in Table 7, can be calculated using Eq. (1).

$$
\begin{aligned}
\tilde{\mathrm{M}}_{1}(+) \tilde{\mathrm{M}}_{2} & =\left(l_{1}, m_{1}, u_{1}\right) \oplus\left(l_{2}, m_{2}, u_{2}\right) \\
& =\left(l_{1}+l_{2}, m_{1}+m_{2}, u_{1}+u_{2}\right)
\end{aligned}
$$

for any two TFNs $\tilde{\mathrm{M}}_{1}=\left(l_{1}, m_{1}, u_{1}\right)$ and $\tilde{\mathrm{M}}_{2}=\left(l_{2}, m_{2}, u_{2}\right)$.

Table 7. Overall pairwise comparison matrix of customer/sales order selection criteria.

\begin{tabular}{c|ccc}
\hline Criteria & $\mathrm{C} 1$ & $\mathrm{C} 2$ & $\mathrm{C} 3$ \\
\hline $\mathrm{C} 1$ & $(1,1,1)$ & $(4.08,4.78,5.5)$ & $(2.06,2.73,3.42)$ \\
$\mathrm{C} 2$ & $(0.75,1.1,1.14)$ & $(1,1,1)$ & $(1.43,1.78,2.14)$ \\
$\mathrm{C} 3$ & $(1.47,1.84,2.25)$ & $(3.39,4.07,4.75)$ & $(1,1,1)$
\end{tabular}

As said by Chang [15] with the concept of extend analysis, if $X=\left\{x_{1}, x_{2}, \ldots x_{\mathrm{n}}\right\}$ is an object set, and $\mathrm{U}=$ $\left\{u_{1}, u_{2}, \ldots, u_{\mathrm{m}}\right\}$ is a goal set, each object will be taken and perform extent analysis for each goal respectively. Thus, a total of $m$ extent analysis values for each object, are denoted as:

$M_{g_{5}}^{1}, M_{g^{5}}^{2}, \ldots, M_{g^{5}}^{m}, \quad$ where $i=1,2, \ldots, \mathrm{n}$.

With respect to Eq. (2), it represents the values of extent analysis of $i^{\text {th }}$ Object for $m^{\text {th }}$ goals. Thus, the fuzzy synthetic extent with respect to the $i^{\text {th }}$ object is described as:

$$
F_{i}=\sum_{j=1}^{m} M_{g i}^{j} \otimes\left[\sum_{i=1}^{n} \sum_{j=1}^{m} M_{g i}^{j}\right]^{-1}
$$

Using Eq. (3), the the fuzzy synthetic extent value with respect to each of the three criteria is calculated, denoted by $\mathrm{F}_{1}, \mathrm{~F}_{2}$, and $\mathrm{F}_{3}$ respectively.

$$
\begin{gathered}
\mathrm{F}_{1}=(11.65,13.74,15.89) \otimes(69.83,60.9,52.22)^{-1} \\
=(0.17,0.23,0.3) \\
\mathrm{F}_{2} \quad=(6.94,8.66,10.39) \otimes(69.83,60.9,52.22)^{-1} \\
=(0.1,0.14,0.2) \\
\mathrm{F}_{3}=\left(11.42, \begin{array}{c}
13.53,15.75) \otimes(69.83,60.9,52.22)^{-1} \\
=
\end{array}\right. \\
\quad(0.16,0.22,0.3)
\end{gathered}
$$


Since there are more than one decision maker to evaluate the relative importance of the criteria and the relative value of the alternatives to the specific criteria, the fuzzy value lines within the fuzzy family would be explained by equations stated below.

The degree of possibility of $\mathrm{M}_{1} \geq \mathrm{M}_{2}$ is expressed as:

$$
V\left(M_{1} \geq M_{2}\right)=\sup _{x \geq y}\left[\min \left(\mu_{M_{1}}(x), \mu_{M_{z}}(y)\right)\right]
$$

When a pair $(\mathrm{x}, \mathrm{y})$ exists such that $\mathrm{x} \geq \mathrm{y}$ and $\mu_{\mathrm{M} 1}(\mathrm{x})=$ $\mu_{\mathrm{M} 2}(\mathrm{y})=1$, then $V\left(M_{1} \geq M_{2}\right)=1$. Since $\mathrm{M}_{1}$ and $\mathrm{M}_{2}$ are convex fuzzy numbers, thus,

and

$$
V\left(M_{1} \geq M_{2}\right)=1 \text { if } \mathrm{m}_{11} \geq \mathrm{m}_{21}
$$

$$
V\left(M_{2} \geq M_{1}\right)=\operatorname{hgt}\left(\mathrm{M}_{1} \cap \mathrm{M}_{2}\right)=\mu_{\mathrm{M} 1}(\mathrm{~d})
$$

where $d$ is the ordinate of the highest intersection point $\mathrm{D}$ between $\mu_{\mathrm{M} 1}$ and $\mu_{\mathrm{M} 2}$, as illustrated in Fig. 1 .

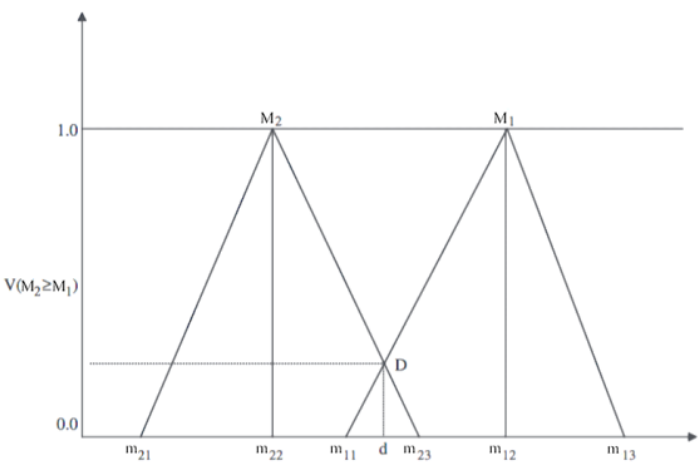

Fig. 1. Intersection between $M_{1}$ and $M_{2}$

When $\mathrm{M}_{1}=(\mathrm{m} 11, \mathrm{~m} 12, \mathrm{~m} 13)$ and $\mathrm{M}_{2}=(\mathrm{m} 21, \mathrm{~m} 22$, $\mathrm{m} 23$ ), then $\mathrm{d}$ can be calculated by Eq. (7), which is

$$
\mathrm{d}=\frac{m_{11}-m_{28}}{\left(m_{22}-m_{28}\right)-\left(m_{12}-m_{11}\right)}
$$

In order to compare $\mathrm{M} 1$ and $\mathrm{M} 2$, both values of $V\left(M_{1} \geq M_{2}\right)$ and $V\left(M_{2} \geq M_{1}\right)$ are needed.

Therefore, the degree of possibility of $F_{i}$ over $F_{j}$, where $i$ $\neq \mathrm{j}$, are computed by using Eq. (5), (6), and (7). The results are summarized in Table 8 .

Table 8. The degree of possibility of $F_{i}$ over $F_{j}$.

\begin{tabular}{|l|l|l|}
$V\left(F_{1} \geq F_{2}\right)=1$ & $V\left(F_{2} \geq F_{1}\right)=0.28$ & $V\left(F_{3} \geq F_{1}\right)=0.98$ \\
$V\left(F_{1} \geq F_{3}\right)=1$ & $V\left(F_{2} \geq F_{3}\right)=0.31$ & $V\left(F_{3} \geq F_{2}\right)=1$ \\
\hline
\end{tabular}

The possibility degree of a convex fuzzy number to be larger than $k$ convex fuzzy number $M_{\mathrm{i}}(i=1,2, \ldots, k)$ can be searched by:

$$
\begin{gathered}
V\left(M \geq M_{1}, M_{2}, \ldots, M_{\mathrm{k}}\right) \\
=V\left[\left(M \geq M_{1}\right) \text { and }\left(M \geq M_{2}\right) \text { and } \ldots \text { and }\left(M \geq M_{\mathrm{k}}\right)\right] \\
=\min V\left(M \geq M_{\mathrm{i}}\right), \quad i=1,2, \ldots, k .
\end{gathered}
$$

Assume that, for $k=1,2, \ldots, n ; k \neq i$,

$$
d^{\prime}\left(X_{i}\right)=\min V\left(\mathrm{~F}_{\mathrm{i}} \geq \mathrm{F}_{\mathrm{k}}\right),
$$

Then the weight vector is denoted by

$$
W^{\prime}=\left(d^{\prime}\left(X_{1}\right), d^{\prime}\left(X_{2}\right), \ldots, d^{\prime}\left(X_{n}\right)\right)^{\mathrm{T}},
$$

where $X_{i}(i=1,2, \ldots, n)$ are $n$ elements.

Finally, by normalization, the normalized weight vectors can be obtained by

$$
W=\left(d\left(X_{1}\right), d\left(X_{2}\right), \ldots, d\left(X_{n}\right)\right)^{\mathrm{T}},
$$

where $W$ is a non-fuzzy number and present the priority weight of the attributes.

With regards to the Eq. (10), the minimum degrees of possibility are obtained as:

$$
\begin{gathered}
d^{\prime}\left(\mathrm{C}_{1}\right)=\min V\left(F_{1} \geq F_{2}, F_{3}\right) \\
=\min (1,1) \\
=1
\end{gathered}
$$

Likewise, $d^{\prime}\left(\mathrm{C}_{2}\right)=0.28$ and $d^{\prime}\left(\mathrm{C}_{3}\right)=0.98$.

Therefore, the weight vector would be:

$$
\mathrm{W}^{\prime}=(1,0.28,0.98)^{\mathrm{T}}
$$

By applying normalization of the weight vector with respect to the three decision criteria (i.e. $\mathrm{C}_{1}, \mathrm{C}_{2}, \mathrm{C}_{3}$ ),

$$
\mathrm{W}=(0.44,0.12,0.43)^{\mathrm{T}}
$$

After running the computation for the weighting of the main criteria (in level 2 of the AHP hierarchy), the comparisons of different sub-criteria are made under each criteria separately according to the same procedures as discussed above. Then, the sub-criteria's comparison matrices and their weight vectors are concluded in Table 9-11.

Table 9. Fuzzy pairwise comparison matrix of sub-criteria with respect to criterion $\mathrm{C} 1$.

\begin{tabular}{c|ccc}
\hline $\mathrm{C} 1$ & $\mathrm{~S} 1$ & $\mathrm{~S} 2$ & Weight \\
\hline $\mathrm{S} 1$ & $(1,1,1)$ & $(3.42,4.11,4.83)$ & $\mathbf{0 . 6 8}$ \\
$\mathrm{S} 2$ & $(0.76,1.11,1.47)$ & $(1,1,1)$ & $\mathbf{0 . 3 2}$
\end{tabular}

Table 10. Fuzzy pairwise comparison matrix of sub-criteria with respect to criterion $\mathrm{C} 2$.

\begin{tabular}{c|cccc}
\hline C2 & S3 & S4 & S5 & Weight \\
\hline S3 & $(1,1,1)$ & $(0.79,1.15,1.55)$ & $(0.78,1.13,1.5)$ & $\mathbf{0 . 0 5}$ \\
S4 & $(3.08,3.78,4.5)$ & $(1,1,1)$ & $(1.5,1.89,2.33)$ & $\mathbf{0 . 4 8}$ \\
S5 & $(2.75,3.44,4.17)$ & $(1.39,2.07,2.75)$ & $(1,1,1)$ & $\mathbf{0 . 4 7}$
\end{tabular}


Table 11. Fuzzy pairwise comparison matrix of sub-criteria with respect to criterion $\mathrm{C} 3$.

\begin{tabular}{c|cccc}
\hline C3 & S6 & S7 & S8 & Weight \\
\hline S6 & $(1,1,1)$ & $(3.3 .3,4.33,5.33)$ & $(2.09,2.44,2.8)$ & $\mathbf{0 . 3 8}$ \\
S7 & $(0.21,0.27,0.39)$ & $(1,1,1)$ & $(0.81,1.18,1.58)$ & $\mathbf{0 . 2 2}$ \\
S8 & $(3.71,4.38,5.06)$ & $(2.08,2.78,3.5)$ & $(1,1,1)$ & $\mathbf{0 . 4 0}$
\end{tabular}

With the weightings of each criteria and sub-criteria identified, the ISOAS is able to identify the score of each customer order (i.e. candidate), thereby obtain the priority weighting of each customer order for order selection.

\section{Results and discussion}

\subsection{Key performance improvements}

With an implementation of ISOAS in the case company for one-month, there is a noticeable improvement in terms of the efficiency in making customer order selection.

\subsubsection{Decision making efficiency}

The processing time of decision making for order allocation problems are measured before and after the ISOAS implementation. The time is recorded during the one-month time of August 2017 (before implementation) and March 2018 (after implementation) separately. Overall, the average processing time of decision making per order allocation issue is greatly decreased from 54.3 minutes to 17 minutes. The decision making efficiency has increased by $68.7 \%$ with the use of ISOAS. The performance is summarised in Table 12.

Table 12. Processing time (in minutes) of decision making for order allocation problem before-and-after ISOAS implementation.

\begin{tabular}{|c|c|c|c|}
\hline Operation & Before & After & Diff. \\
\hline Data collection & 10.5 & 10.5 & - \\
\hline Data input in ISOAS & 0 & 6.5 & - \\
\hline Decision generation & 33.8 & 0.5 & $98.5 \%$ \\
\hline Total & 54.3 & 17 & $68.7 \%$ \\
\hline
\end{tabular}

\section{Conclusion}

A fuzzy-AHP approach and rule-based system for decision making process in order allocation has been developed. This approach enables the selection of desired sales orders based on multiple criteria which may be quantitative or qualitative in nature, according to the judgment of scholars and domain experts. In fuzzy-AHP module, the customer orders are prioritized with respect to the values according to their performance under each decision making attributes. The degree of confidence of the decision judgements are quantified through the spread of fuzzy numbers with fuzzy pairwise comparison calculations. The approach can transform the fuzziness of human preference into the measurable number, enabling the operation of the AI-based system to assist humans in decision-making. Researchers are suggested to further develop and integrates artificial intelligence techniques in the areas of order management in supply chains.

The authors wish to thank the Research Office of The Hong Kong Polytechnic University for supporting the project (Project Code: RU5T).

\section{References}

1. S. Shingo, CRC Press (1988)

2. J. Olhage, D.I. Prajogo, Omega, 40(2), 159-165. (2012)

3. S. Hemmati, M. Rabbani, Int J Adv Des Manuf Tech, 48(5-8), 801-813 (2010)

4. S. Sharma, Optimization Letters, 3(2), 239-251 (2009)

5. P.D. Berger, N.I. Nasr, J Interact Market, 12(1), 17-30 (1998)

6. L. Ryals, J Market, 69(4), 252-261 (2005)

7. R. Venkatesan, V. Kumar, T. Bohling, J Market Res, 44(4), 579-594 (2007)

8. R.K. Gavade, Int J Comput Sci Inform Tech, 5(4), 5643-5646 (2014)

9. T. L. Saaty, The analytic hierarchy process: planning, priority setting, resources allocation. (New York: McGraw, 281, 1980).

10. S. Zahir, Eur J Oper Res, 112(3), 620-634 (1999)

11. F.T. Chan, N. Kumar, Omega, 35(4), 417-431 (2007)

12. K. Shaw, R. Shankar, S.S. Yadav, L.S. Thakur, Expert Syst Appl, 39(9), 8182-8192 (2012)

13. G. Büyüközkan, G. Çifçi, S. Güleryüz, Expert Syst Appl, 38(8), 9407-9424 (2011)

14. X. Wang, H.K. Chan, R.W. Yee, I. Diaz-Rainey, Int J Prod Econ, 135(2), 595-606 (2012).

15. D.Y. Chang, Eur J Oper Res, 95(3), 649-655 (1996). 